\title{
AS APORIAS DAS CONFISSÕES AGOSTINIANAS
}

\author{
Emmanuel Bermon \\ Professor titular de filosofia medieval \\ Université Bordeaux-Montaigne
}

\begin{abstract}
RESUMO: O tema deste artigo é evidenciar algumas aporias encontradas por Agostinho ele deseja louvar Deus no início das Confissões. A confissão de louvor interfere imediatamente na confissão de fé e na confissão de pecado, e todas as três são indissociáveis, de tal maneira que é difícil saber por qual delas começar. Se a fé torna possível a invocação que precede o conhecimento e o louvor de Deus, não é absurdo invocar Deus, na medida em que ele está presente naquele o chama? E que se diz quanto se fala de Deus? A linguagem humana não atinge sua finalidade senão no fracasso em parlar adequadamente de Deus. Essas aporias do proêmio das Confissões culminam numa contradição soberana formulada no De doctrina christiana: a qual consiste em dizer Deus inefável. Ainda que a contradição seja logicamente insuperável, Agostinho interdiz que se cale a respeito de Deus e encontra uma solução pratica ao problema da inefável inefabilidade de Deus num ato de fala de jubilação. ${ }^{1}$
\end{abstract}

Palavras-chave: Agostinho, Confissões, Inefável, Linguagem, louvor.

RÉSUMÉ : L'objet de cet article est de mettre en évidence certaines apories rencontrées par Augustin lorsqu'il veut louer Dieu au début des Confessions. La confession de louange interfère immédiatement avec la confession de la foi et celle du péché, qui sont toutes trois indissociables, de sorte qu'il est difficile de savoir par laquelle commencer. Si la foi rend possible l'invocation, qui précède la connaissance et la louange de Dieu, n'y a-t-il pas quelque chose d'absurde à invoquer Dieu, dans la mesure où il est toujours déjà présent dans celui qui l'appelle ? Et que dit-on lorsqu'on parle de Dieu ? Le langage humain n'atteint-il pas son but en échouant à parler adéquatement de Dieu. Ces apories du début des Confessions culminent dans une contradiction souveraine formulée dans le De doctrina christiana : celle qui consiste à dire Dieu ineffable alors que rien ne peut être dire de lui s'il est vrai qu'il est ineffable. Bien que la contradiction soit logiquement indépassable, Augustin interdit que l'on taise au sujet de Dieu et trouve une solution pratique au problème de l'ineffable ineffabilité de Dieu dans l'acte de parole de la jubilation.

Mots-clef: Augustin, Confessions, ineffable, langage, louange.

\section{Agradecimentos e apresentação}

Este texto foi originalmente apresentado como uma conferência na Universidade Federal do ABC, em 10 de abril de 2018. O convite para tal ocasião surgiu quando conheci

\footnotetext{
1 Tradução Pedro Calixto et Cristiane N. A. Ayoub.
} 
Cristiane N. A. Ayoub e discutimos sobre as Confissões de Santo Agostinho: eu lhe disse na ocasião que me parecia difícil administrar aulas sobre essa obra, porque sua introdução é bastante árdua; ora, deve-se necessariamente começar pelo começo... dever-se-ia começar pelo começo. Assim, a convite de Cristiane, tentarei evidenciar as dificuldades colocadas no início da obra. Para tanto, inicialmente farei algumas considerações sobre a noção de "confissão"; em seguida, mostrarei quais aporias revelam concretamente às confissões nos quatro primeiros capítulos do Livro I; e, finalmente, veremos como essas aporias culminam em uma contradição soberana, que é explicitada no De doctrina christiana, e que consiste em dizer o Deus inefável, embora nada possa ser dito dele, se for verdade que ele é inefável.

Esta versão do texto teve a parte de agradecimentos e apresentação adaptada pelo Prof. Pedro Calixto, a quem expresso meus sinceros agradecimentos. ${ }^{2}$

\section{A noção de "confissões".}

As confissões agostinianas se caracterizam essencialmente pelo fato de que são uma palavra dirigida a Deus. "Magnus es, domine, et laudabilis valde" ("Tu es grande, Senhor, e demais louvável"3): essas são as primeiras palavras da obra, que retomam um versículo empregado várias vezes nos salmos (S1 47,1; 95,4; 144,3). De fato, ao longo de toda obra, Agostinho dirige-se constantemente a Deus. Com exceção do autor do livro dos Salmos, na Bíblia, ninguém, em toda literatura antiga, havia anteriormente escrito um livro inteiramente dirigido a Deus. Nenhum livro fora escrito diante d'Ele, para Ele, com Ele.

Jean-Louis Chrétien colocou em evidência essa singularidade em sua obra Saint Augustin et les actes de parole: "Se Agostinho, com suas Confissões, escreveu, como é admitido por todos, um livro sem igual (...), é unicamente porque ele entrou nu, com sua nudez, na possibilidade que é oferecida a todos nós e a cada um; a possibilidade

2 Agradeço a Cristiane N. A. Ayoub por seu gentil convite, a Pedro Calixto e Moacyr Novaes pela tradução consecutiva da conferência no dia de sua apresentação, bem como ao debatedor Moacyr Novaes.

3 AGOSTINHO, Confissões, I, 1, 1, p. 38. A paginação encontrada ao final das referências bibliográficas às Confissões, sempre que o texto é citado em português, referem-se à tradução do latim elaborada por Lorenzo Mammì em SANTO AGOSTINHO, Confissões. Prefácio e tradução de Lorenzo Mammì. 2a ed. São Paulo: 
simultaneamente universal e individualizante de tornar-se (a si mesmo) na verdade diante de Deus, coram Deo, cessando de fugir e de se velar, pelo ato de confessá-lo e de se confessar a ele". ${ }^{4}$

Se a confissão é fundamentalmente uma palavra proferida diante de Deus, "coram Deo", é necessário esclarecer que "esse diante do quê essa palavra se dá não lhe é acrescentado, mas funda sua própria possibilidade". 5 Deus não é o destinatário de uma palavra que Agostinho escolheria lhe dirigir após tê-la formulado por si mesmo. O fato de que ela seja dita diante de Deus é essencial para essa palavra, a qual só pode nascer e ser o que ela é pelo fato de que ela se dirige a Deus, que é a sua condição de possibilidade.

Certamente, para Agostinho, Deus é a condição de possibilidade de toda palavra verdadeira enquanto verdadeira. De modo geral, essa afirmação vale para toda verdade racional que pode ser proferida. Por exemplo, se eu digo com certeza que $2+2=4$ ou que os sábios são melhores que os tolos, é porque recebo o ensinamento de Deus ao consultar a verdade que está em mim (segundo a célebre tese do De Magistro), e isso independe de minha crença ou não na existência de Deus. No entanto, a confissão é uma palavra verdadeira de um tipo singular: ela somente é possível na medida em que é formulada consciente e explicitamente diante de Deus, o qual é reconhecido como fonte de toda verdade. Dito isso, o que a confissão confessa?

Como se sabe, para Agostinho, há principalmente três confissões: a confissão de fé (confessio fidei), a confissão de pecado (confessio peccati) e a confissão de louvor (confessio laudis). 6 "Confiteor" significava inicialmente, em latim clássico, apenas "admitir, reconhecer um erro". Com o latim cristão, aparece o sentido novo de "confissão de fé" e, então,

Penguin Classics Companhia das Letras, 2017.

4 "Si Augustin, avec ses Confessions, a écrit, de l'aveu de tous, un livre à nul autre pareil (...), c'est uniquement parce qu'il est entré avec nudité, avec sa nudité, dans cette possibilité offerte à tous et à chacun, cette possibilité à la fois commune et individualisante, celle de devenir soi-même en vérité devant Dieu, coram Deo, en cessant de se fuir et de se voiler, par l'acte de le confesser et de se confesser à lui". J.-L. Chrétien, Saint Augustin et les actes de parole, Paris, PUF, 2002, p. 122.

5 "Ce devant quoi cette parole se tient ne lui est pas surajouté, mais fonde sa possibilité même". J.-L. Chrétien, op. cit., p. 130. 
"confiteri", passa a significar reconhecer a própria fé com palavras (por exemplo, no momento da recitação do Símbolo) e atos. Com esse segundo sentido aparece um terceiro, também novo: o de louvar. Confessiones, portanto, são três títulos em um, daí o plural. Há muitas confissões, mas elas também são de naturezas diversas: confissão da fé, dos pecados e do louvor.

Examinemos, agora, como os três sentidos de "confessio" se ordenam uns em relação aos outros. Parece que as três confissões estão ligadas entre si de tal maneira que, pelo menos nesta vida, uma não se dá sem as outras duas. Ocorre com as confissões o mesmo que com as virtudes, que só podem ser possuídas em conjunto, segundo a doutrina da antakolouthia, isto é, da conexão das virtudes (só se pode ser corajoso, por exemplo, se também se é sábio, sem o que se demonstra temeridade e não coragem). Portanto, a confissão é necessariamente tridimensional; ela sempre implica essas três possibilidades da palavra. Percebe-se isso, ao que me parece, na prece de abertura das Confissões.

\section{A prece inaugural das Confissões.}

\section{A vontade de louvar Deus.}

Já citei o início da obra: "Magnus es, domine, et laudabilis valde" ("Tu és grande, Senhor, e louvável demais"). Trata-se de uma confissão de louvor que abra a obra, se se admite que dizer de Deus que ele é digno de louvor, já é louvá-lo de alguma maneira. Porém, é importante notar que essas primeiras palavras são um citação escritural, que Agostinho assume por conta própria, pois ele tem fé na palavra do salmista, que louva Deus. Que a primeira palavra de Agostinho para Deus não seja sua, mas venha da Bíblia, atesta que ela é (também) uma confissão de fé.

Em seguida, vem a primeira palavra do próprio Agostinho: "et laudare te uult homo...": "Quer te louvar o homem, fragmento qualquer de tua criação, e anda em círculos carregando

6 Cf. Les Confessions I-VII, Paris, Desclée de Brouwer, 1972, "La Bibliothèque Augustinienne", vol. 13, p. 9 sq. 
sua mortalidade, anda em círculos carregando a prova de seu pecado".7 Agostinho afirma, logo de início, que quer louvar Deus. Essa vontade é o fio condutor que lhe permitirá ultrapassar as aporias que ele encontrará (um pouco como a vontade de ser feliz guia a totalidade da meditação do livro $\mathrm{X}$ das Confissões). De fato, não se pode louvar Deus de improviso, pois ninguém se dirige a ele como se dirige a qualquer outra pessoa. Em Agostinho, há a consciência de que, para um homem, a ambição de louvar Deus é imensa.

Como escreve Moacyr Novaes, que consagrou um belo estudo a esse texto em Agostinho ou a razão em exercício, 8 "A composição de diversos textos escriturários permite que Agostinho inaugure suas Confissões elaborando um paradoxo fundamental para o conjunto de sua obra: o reconhecimento de um contraste entre a natureza divina e a natureza humana. Paradoxo, em primeiro lugar, porque a confissão, sendo humana, não pode se arrogar ela mesma capaz de exprimir justamente aquilo que vê à distância: a grandeza divina. Paradoxo, então, porquanto é reconhecimento de um abismo humanamente intransponível". ${ }^{9}$

A designação do homem como trazendo em torno de si o testemunho de sua mortalidade e de seu pecado é uma confissão do pecado. Agostinho se espanta que seja possível querer louvar Deus, como ele mesmo quer, quando se é um homem, mortal, pecador, orgulhoso. Ele responde, no entanto, que é o próprio Deus que colocou esse desejo no coração do homem. Eis, sem dúvida, a frase mais célebre das Confissões: "Tu o incitas, para que goste de te louvar, porque tu nos fizeste rumo a ti e nosso coração é inquieto, até repousar em ti".10

Portanto, o próprio Deus quer que o homem o louve ou, mais precisamente, que sinta prazer em louvá-lo (uma discreta alusão ao dom do Espírito Santo): o louvor não é a realização de um pensum, mas uma antecipação do soberano bem, do qual Deus toma a

7 SANTO AGOSTINHO, Confissões, I, 1, 1, p. 37.

8 Cf. M. Novaes, A Razão em exercício. Estudos sobre a filosofia de Agostinho, São Paulo, Discurso Editorial, 2007, p. 129-138 ("A necessidade de uma dupla descrição de Deus").

9 Op. cit., p. 129.

10 SANTO AGOSTINHO, Confissões, I, 1, 1, p. 37. (com alteração na tradução feita pelos tradutores deste artigo de Bermon). Note-se que, na tradução francesa citada por Emmanuel Bermon, lê-se que Deus "pousse" (incita, empurra) o homem a louvá-lo, e que o coração humano encontra-se "sans repos" (sem repouso) enquanto não "demeure" (permanece) em Deus (N.Ts.). 
iniciativa. Dito isso, como nota Moacyr Novaes, "o paradoxo é ainda maior se tal esforço de louvor, esforço de dizer o divino com palavras humanas, não resulta de uma presunção do homem, mas sim de um comando de Deus: é o Deus transcendente quem exige o louvor". ${ }^{11}$

\section{O problema do começo.}

Uma vez legitimado o desejo de louvar Deus, como realizá-lo? Por onde começar? Agostinho pergunta se a primeira coisa a se fazer é invocar Deus (isto é, chamá-lo em si) ou louvá-lo. A resposta implícita à questão é que inicialmente se deve invocá-lo - o que tem como efeito o adiamento do início do louvor. Isso é deduzido a partir de uma segunda questão de Agostinho, a qual se segue imediatamente à formulação da primeira: o que vem primeiro é conhecer Deus ou invocá-lo? Aqui, há uma dificuldade, pois, se Deus não for conhecido, não há o risco de invocar um outro qualquer em seu lugar? Assim, poderia haver engano na invocação.

No livro $\mathrm{X}$ do De Trinitate, Agostinho avança um argumento semelhante, mas a respeito do espírito humano: se o espírito humano se busca a fim de se conhecer, como ele sabe que aquilo que ele busca e que ele talvez encontrará é ele mesmo, pois ele poderia se tomar como um outro de si mesmo... Ao que é preciso responder que o espírito sempre já se conhece a si mesmo, quando ele se busque, pois ele se conhece buscando-se. ${ }^{12}$ Em nossa passagem das Confissões, que trata da busca de Deus, o problema não é desenvolvido. Agostinho afirma simplesmente que inicialmente é necessário invocar Deus para conhecê-lo, e ele encadeia a pergunta: como invocarei Deus se eu não creio nele?

Mas Agostinho avança muito rápido: não diz, como fará no Livro X das Confissões ou no Livro X do De Trinitate, que para buscar Deus a fim de conhecê-lo, é preciso em certo sentido conhecê-lo, mesmo que esse pré-conhecimento não seja certamente idêntico àquele

11 M. Novaes, A Razão em exercício. Estudos sobre a filosofia de Agostinho, p. 131.

12 Cf. De Trinitate, X, 4, 6. 
que se obtém quando finalmente se encontra Deus. Por exemplo, é preciso que eu já saiba o que é ser grande para que eu possa crer que Deus é grande e, por isso, digno de louvor.

Aqui Agostinho contenta-se em afirmar o primado da crença em relação à invocação, ao conhecimento e ao louvor. Logo, a confissão da fé (confessio fidei) é primeira segundo a ordem das razões, ao passo que, segundo a ordem subjetiva, o que é primeiro é a vontade de louvar. Fundando-se em dados escriturários (especialmente Rm 10,14) e também em sua experiência pessoal, Agostinho conclui esse ponto afirmando que é preciso, em ordem, invocar Deus acreditando na pregação de Cristo; buscar Deus invocando-o, encontrá-lo (e conhecê-lo) buscando-o, e louvá-lo encontrando-o. Mas certamente não se deve representar essa ordem como um processo finito. Como Agostinho diz frequentemente, deve-se buscar Deus para encontrá-lo e, ao encontrá-lo, buscá-lo ainda mais, pois ele é imenso. ${ }^{13}$

\section{A invocação}

Todavia, surge uma nova aporia. Agostinho continua mostrando que invocar Deus crendo nele apresenta algo de impossível: "E como invocarei o meu Deus, meu Deus e Senhor, já que certamente, ao invocá-lo, o chamo para dentro de mim? (...) por que peço que venhas para dentro de, eu que não seria, se já tu não estivesses em mim? (...) Por que te invoco, se estou em ti? De onde virias a mim?"14 (Conf. I, 2, 2) ("Et quomodo invocabo deum meum, deum et dominum meum, quoniam utique in me ipsum eum vocabo, cum invocabo eum ? (...) quid peto ut venias in me, qui non essem nisi essens in me? (...) quo te invoco, cum in te sim? aut unde venias in me?"). Para compreender essa passagem, é preciso ter em mente que Agostinho joga com a etimologia de "invocare", que é formado a partir de "vocare in", literalmente "chamar dentro". "Invocar Deus [invocare] é etimologicamente chamá-lo para vir, para vir aqui, para vir em nós [vocare in], onde, contudo, como criador que mantém

13 Cf. por exemplo In Iohannis Evangelium Tractatus, 63, 1.

14 SANTO AGOSTINHO, Confissões, I, 2, 2, p. 38. 
todas as coisas no ser, ele já está". ${ }^{15}$

\section{O que é Deus?}

À questão do "como?" (quomodo) segue-se, no parágrafo 4, a do "o quê?" (quid), que é a questão do destinatário da invocação, a saber, o próprio Deus. É então que Agostinho profere este magnífico apelo a Deus:

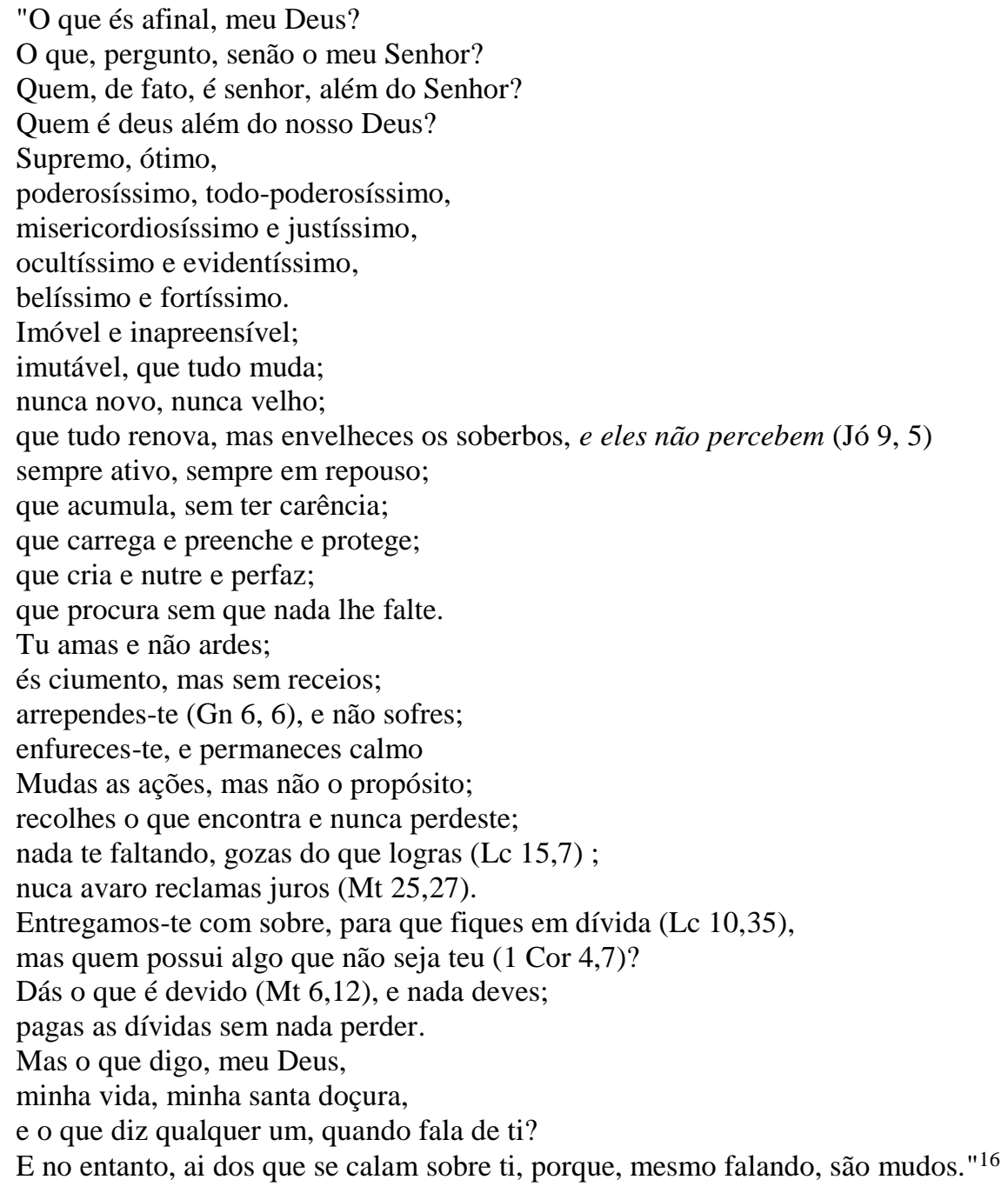

15 J.-L. Chrétien, La Joie spacieuse. Essai sur la dilatation, Paris, Minuit, 2007, p. 37.

16 SANTO AGOSTINHO, Confissões, I, 4, 4, pp. 39-40. O texto supracitado em português e versificado, segue duas orientações distintas, mas decidimos manter a excelente tradução de Lorenzo Mammì (não versificada) e a opção de Emmanuel Bermon de citar a versificação proposta pela edição francesa da Bibliothèque Augustinienne. Contudo, cabe salientarmos o preço de tal versificação segundo a advertência de Mammì, no seu prefácio das Confissões: "A edição francesa da Bibliothèque Augustinienne acentua esse dualismo ao traduzir os 
Trata-se de uma prece recheada de conceitos filosóficos e de referências extraídas das Escrituras (sem as quais ela é incompreensível) e tão complexa que pode-se duvidar que Agostinho fizesse uma assim todos os dias antes de se deitar e de se levantar... Como escreveu James O’Donnell, "as limitações da linguagem humana são manifestadas pelos paradoxos que a natureza divina obriga Agostinho a enunciar (...). As palavras humanas, utilizadas pelos homens, fracassam em presença do divino e tudo que pode ser dito é apenas aproximativo e, quanto ao essencial, o discurso dos homens fracassa em dizer o que quer que seja a respeito de Deus". ${ }^{17}$ Com certeza, mas também é necessário ver que essa falha da linguagem é paradoxalmente um sucesso na medida em que pelo menos permite falar de Deus da melhor maneira. Eu cito ainda Moacyr Novaes: essa prece "apresenta uma linguagem literariamente eficaz, na medida em que for capaz de exibir o conteúdo de sua fé, que será então desdobrado ao longo dos treze livros das Confissões". ${ }^{18}$ Moacyr Novaes tem toda razão em insistir no fato de que, mesmo se tratando de uma "estratégia negativa", "não podemos desconsiderar sem mais os atributos divinos, como se nada dissessem positivamente, quer dizer, como se o seu uso, metafórico, se restringisse a apontar o quanto não entendemos a natureza divina". ${ }^{19}$

segmentos laudatórios em versos livres, os narrativos e argumentativos em prosa. Do ponto de vista estilístico, o recurso se justifica pelo uso, em muitos trechos das Confissões, da assim chamada prosa rítmica, caracterizada por regularidades e simetrias acentuadas na construção das frases e na distribuição dos acentos, próximas ao que hoje entendemos como poesia. Vale lembrar, no entanto, que na época a prosa rítmica era um recurso oratório (que o próprio Agostinho justifica em $A$ instrução cristã, Livro IV), e não poético. De um modo geral, a solução adotada pelos tradutores da Bibliothèque Augustinienne acerta ao marcar os constantes saltos de registro que caracterizam o estilo das Confissões, mas talvez polarize excessivamente uma escrita muito complexa e nuançada. Do ponto de vista conceitual, a delimitação das partes de louvor e confissão (no sentido moderno), implicando a simples justaposição dos dois significados, não renunciaria cedo demais a encontrar um sentido unitário mais profundo? Não reduziria a questão, no limite, ao plano superficial de uma mera homonímia?" (Mammì, Prefácio, p. 15). (N.T.s)

17 "The limitations of human language are displayed by the paradoxes in which the divine nature compels Augustine to speak. (...) Human words used by humans fail in the presence of the divine, and whatever can be said is only approximation, and most human discourse fails to say anything of God at all" (James O'Donnell, "Augustine's Idea of God", Augustinian Studies, 25, 1994, p. 25-36, p. 26).

18 Op. cit., p. 133.

19 O autor continua: "Nesse sentido, dizer que Deus é presente serviria apenas para denunciar a impossibilidade de descrevê-lo corretamente como secreto, e vice-versa. É verdade que este sentido apofático da teologia pode ser encontrado explicitamente em certos páginas de Agostinho, como veremos a seguir, mas é justificado supor que aqui, nas Confissões, não se trate exclusivamente disso " (op. cit., p. 135). 
Por falta de tempo, devo me contentar-me em assinalar nessa prece a presença de cinco formas significativas de discurso, que frequentemente se acumulam: (1) as tautologias (bíblicas) ("Quem, de fato, é senhor, além do Senhor? Quem é deus além do nosso Deus?); (2) as hipérboles, expressas pelos superlativos ou mesmo pelos superlativos de superlativos (Deus "supremo", "ótimo", "poderosíssimo", "todo-poderosíssimo" [omnipotentissime]); (3) as contradições, que atestam em "Deus" uma "coincidentia oppositorum" ("ocultíssimo e evidentíssimo"; "sempre ativo, sempre em repouso"); (4) as inconveniências, que consistem em atribuir a Deus paixões, como o faz a Bíblia, mesmo se o antropomorfismo é corrigido pela afirmação de que essas paixões são vividas na impassibilidade (Deus "ciumento", mas despreocupado, "enfurecido", mas tranquilo, "amante" sem fervor, "arrependido" sem sofrimento...); (5) as afirmações desconcertantes quanto à maneira em que Deus "mantém contas" com os homens... A respeito disso, Agostinho realiza uma "montagem" de citações escriturárias particularmente impressionante." Credor, Deus reclama juros, mostra-se ávido pelo ganho, tem exigências de usurário; porém, não desembolsa nada, ele que jamais é indigente ou avaro. Faz questão de ser devedor, ainda que tudo seja seu; ele paga suas dívidas, embora não deva a ninguém; ele perdoa dívidas, sem nada perder". ${ }^{20}$

Desconcertado por suas próprias afirmações, o próprio Agostinho pergunta finalmente: "Mas o que digo, meu Deus (...), e o que diz qualquer um, quando fala de ti?" E contudo, ele logo encadeia, para se justificar, uma terrível imprecação: "Et vae tacentibus de te quoniam loquaces muti sunt" ("ai dos que se calam sobre ti, porque, mesmo falando, são mudos."). ${ }^{21}$ Agostinho ataca todos aqueles que não falam de Deus e os trata como mudos (por mais prolixos que sejam). Pois, falar calando-se sobre Deus, é falar em vão, é falar para não dizer nada! É melhor falar impropriamente de Deus do que se calar a seu respeito, seguindo a ideia que não se pode dizer nada que lhe seja digno, já que ele é inefável.

20 "Créancier, Dieu opère des rentrées, se montre âpre au gain, a des exigences d'usurier ; pourtant, il n'a rien déboursé, il n'est jamais indigent ni avare. Il s'arrange pour être débiteur bien que tout soit sien ; il paie ses dettes bien qu'il ne doive à personne ; et s'il remet les dettes, il ne perd rien". A. Solignac, Saint Augustin, les Confessions I-VII, Note complémentaire 3, "Rythme et harmonie du style dans Confessions, I, iv, 4", p. 652-57, p. 654 .

21 Cf. "Vae mihi quia tacui" (Is. 6, 5). 


\section{O paradoxo da inefabilidade divina (De doct. christ. I, 6).}

Uma admirável passagem do De doctrina christiana coloca o problema da inefabilidade divina com toda sua acuidade. Proponho que o examinemos. Agostinho acaba de formular uma profissão de fé breve, mas densa, relativa à Trindade. Ele pergunta: "Dissemos, proferimos algo digno de Deus? Seguramente, eu sinto que eu não queria nada além de falar. Mas, se falei, aquilo que eu disse não é o que eu queria dizer. Como sei disso, senão pelo fato de que Deus é inefável? Ora, se aquilo que foi dito por mim fosse inefável, não teria sido dito" (De doctrina christiana, I, 6). ${ }^{22}$ No caso de Deus, aquilo que se quer dizer e aquilo que é dito têm impossibilidade de coincidir.

Primeiramente, Agostinho se dá conta do emprego paradoxal que ele acaba de fazer da linguagem ao falar de Deus: ele sabe que quis falar de Deus, mas o que ele disse não é aquilo que ele quis dizer. Isso é mostrado com a ajuda de um breve silogismo: Deus é inefável; o que (Agostinho) disse não o é, senão ele não poderia tê-lo dito; logo, o que ele disse não pode ser Deus; portanto, o que ele disse e aquilo que ele queria dizer são duas coisas diferentes.

\section{A inefável inefabilidade de Deus.}

Em seguida, por uma colocação no limite, Agostinho afirma que nem mesmo se pode dizer de Deus que ele é inefável:

"É por isso que Deus não deve sequer ser dito inefável, porque mesmo quando isso é dito, diz-se algo, e é produzido algum combate de palavras (pugna verborum), pois, se o que é inefável, é o que não pode ser dito, então não é inefável aquilo que pode ao menos ser dito inefável. Seria necessário evitar esse combate de palavras pelo

22 De doctrina christiana, I, 6. Tradução do autor. 
silêncio, ao em vez de pacificá-lo falando". ${ }^{23}$

O que é contraditório, não é somente falar do inefável dizendo, por exemplo, que Deus é grande, como no início das Confissões; mas é também dizer que ele é inefável, pois dizer Deus inefável, é ainda dizê-lo e, portanto, contradizer-se. Esse paradoxo "agravado" é notável. Salvo engano de minha parte, Agostinho é o primeiro filósofo a tê-lo formulado explicitamente. Depois dele, tal formulação é encontrada num contexto teológico completamente outro, ${ }^{24} \mathrm{em}$ Damascius, que afirma que "o totalmente inefável é tal que não se pode sequer afirmar a seu respeito que ele é inefável" (De principiis, I, p. 10, 23-24 Westernink). 25

Como resolver tal paradoxo? Agostinho inicialmente parece inclinado ao silêncio. Ele considera seriamente o "combate de palavras" - ou seja, a contradição nos termos da inefável inefabilidade divina -, dado que ele renuncia a "pacificá-lo falando". Em outras palavras, ele renuncia à ideia de que a contradição possa ser "vencida" logicamente. O paradoxo permanece "inexplicável", retomando um termo que Agostinho e, antes dele, os estoicos aplicavam aos problemas insolúveis do tipo do paradoxo do "Mentiroso". O De doctrina christiana poderia ter terminado como o Tractatus de Wittgenstein nesse momento, com a afirmação segundo a qual "Aquilo do que não se pode falar, deve ser calado".

\section{A homenagem da palavra humana.}

Todavia, Agostinho apressa-se em acrescentar: "E, contudo, Deus, ainda que nada de digno possa ser dito sobre ele, aceitou a homenagem da palavra humana, e ele quis que nos alegrássemos através de nossas palavras dirigidas a seu louvor". "Este é o pensamento central

23 Idem.

$24 \mathrm{Cf}$. Ph. Hoffmann, "L'expression de l'indicible dans le néoplatonisme grec, de Plotin à Damascius", in C. Lévy e L. Pernot (eds.), Dire l'évidence (philosophie et rhétorique antiques). Actes du Colloque de Créteil et de Paris, 24-25 mars 1995, Cahiers de philosophie de l'Université de Paris XII-Val de Marne, n. 2, Paris, 1997, p. 335-390.

25 Cf. L. Castagnoli, Ancient Self-Refutation. The Logic and History of the Self-Refutation Argument from Democritus to Augustine, Cambridge, Cambridge University Press, 2010, p. 245. 
de santo Agostinho a esse respeito: aquilo que é o mais difícil de dizer, ao tentar dizê-lo, é o que somos impelidos a dizer, se não quisermos renunciar à nossa dignidade de homens". ${ }^{26}$ De fato, "cada vez que Agostinho evoca a inefabilidade de Deus, é para autorizar e exigir a palavra humana, e não para interditá-la". ${ }^{27} \mathrm{~A}$ esse respeito, ele se refere constantemente às injunções de louvar Deus presentes nos Salmos.

Nesse ponto, poderíamos multiplicar os textos. Para citar apenas um, Deus deve ser "celebrado e honrado indizivelmente" (De libero arbitrio, III, 13, 37). ${ }^{28} \mathrm{O}$ que isso significa? Louvar indizivelmente Deus é, na realidade, "Jubilar". Com efeito, como Agostinho pormenoriza, "jubilar é não poder exprimir sua alegria por palavras, e, no entanto, significar através de cantos aquilo que é sentido no interior de si e que as palavras não podem exprimir" (Enarrationes in Psalmos, 94, 3) ${ }^{29}$. Agostinho oferece uma bela ilustração disso: "Os ceifadores e os vindimistas colhem os frutos de seu trabalho: regozijando-se da fecundidade da terra e de sua fertilidade, eles cantam de alegria; e em meio aos dos cantos cujas palavras (verbis) eles pronunciam, eles misturam certas vozes (voces) sem palavras na elação (in elatione) de seu espíritos exultantes, e isso é chamado de júbilo! Quando estamos em júbilo? Quando louvamos o que não pode ser dito." (Enarrationes in Psalmos, 99, 4-5).

\section{O perigo do silêncio.}

Mas isso não é tudo, e eu concluirei com esse ponto. Agostinho denunciou explicitamente a atitude que consiste em calar-se sobre Deus porque nada de digno pode ser dito dele. "Em seguida, após ter inicialmente estabelecido que é melhor se calar do que falar mal e dizer o que não deveria ser dito, uma homilia sobre os Salmos insiste, ainda com mais ênfase, quanto ao perigo do silêncio". 30

26 "C'est la pensée centrale de saint Augustin à ce propos: ce qui est le plus difficile à dire, à tenter même de dire, c'est cela que nous sommes tenus de dire, si nous ne voulons pas renoncer à notre dignité d'hommes". J.-L. Chrétien, Saint Augustin et les actes de paroles, p. 96.

27 "Chaque fois qu'Augustin évoque l'ineffabilité de Dieu, c'est pour autoriser et exiger la parole humaine, et non pas pour l'interdire". J.-L. Chrétien, op. cit., p. 95.

28 Tradução livre.

29 Sur ce thème, cf. J.-L. Chrétien, op. cit., p. 262.

30 "Une homélie sur les psaumes, après avoir d'abord établi qu'il vaut mieux se taire que de mal parler et de dire 
Agostinho cita o versículo "Eu fiquei surdo, e fui humilhado e silenciei sobre as coisas boas: minha dor se renovou (Obsurdui, et humiliatus sum, et silui a bonis. Et dolor meus renovatus est)" (S1. 38,3). 31 Ao que ele comenta nestes termos: "Devido a um medo excessivo de dizer coisas que não fossem justas (bona), ele resolveu não dizer nada (nulla dicere), nem mesmo as coisas boas (bona); e, uma vez que decidiu se calar, ele começou a não escutar mais" (Enarrationes in Psalmos, 38, 4). ${ }^{32}$ Em suma, calar-se sobre o indizível, sob o pretexto de que não se pode dizer nada de conveniente a seu respeito, tem como consequência funesta o nosso rompimento com ele, tornando-nos surdos à sua presença.

\section{BIBLIOGRAFIA:}

AGOSTINHO, Confissões. Prefácio e tradução de Lorenzo Mammì. 2a ed. São Paulo: Penguin Classics Companhia das Letras, 2017.

AUGUSTIN, Les Confessions I-VII, . A. Solignac (Ed) Paris, Desclée de Brouwer, 1972, "La Bibliothèque Augustinienne", vol. 13.

CHRÉTIEN J.-L., Saint Augustin et les actes de parole, Paris, PUF, 2002.

NOVAES M., A Razão em exercício. Estudos sobre a filosofia de Agostinho, São Paulo, Discurso Editorial, 2007.

AUGUSTIN, La Trinité. (Traduction et notes par M. Mellet, Th. Camelot; Introduction par E. Hendrickx; avantpropos par G. Madec.) Paris: Institut d'Études Augustiniennes, 1997. (Bibliothèque Augustinienne (Euvres de Saint Augustin, n. 15-16. Vol. I : Livres I-VII; Vol. II: Livres IX-XV.)

CHRÉTIEN J.-L., La Joie spacieuse. Essai sur la dilatation, Paris, Minuit, 2007.

O'DONNELL J., "Augustine's Idea of God", in Augustinian Studies, 25, 1994.

HOFFMANN Ph., "L'expression de l'indicible dans le néoplatonisme grec, de Plotin à Damascius", in C. Lévy e L. Pernot (eds.), Dire l'évidence (philosophie et rhétorique antiques). Actes du Colloque de Créteil et de Paris, 24-25 mars 1995, Cahiers de philosophie de l'Université de Paris XII-Val de Marne, n. 2, Paris, 1997, p. 335-390.

CASTAGNOLI L., Ancient Self-Refutation. The Logic and History of the Self-Refutation Argument from Democritus to Augustine, Cambridge, Cambridge University Press, 2010

ce qu'on ne devrait pas dire, insiste ensuite avec plus de force encore sur le danger du silence". J.-L. Chrétien, op. cit., p. 96.

31 Enarratio in Psalmum 38, 4. Tradução livre.

32 Idem. 